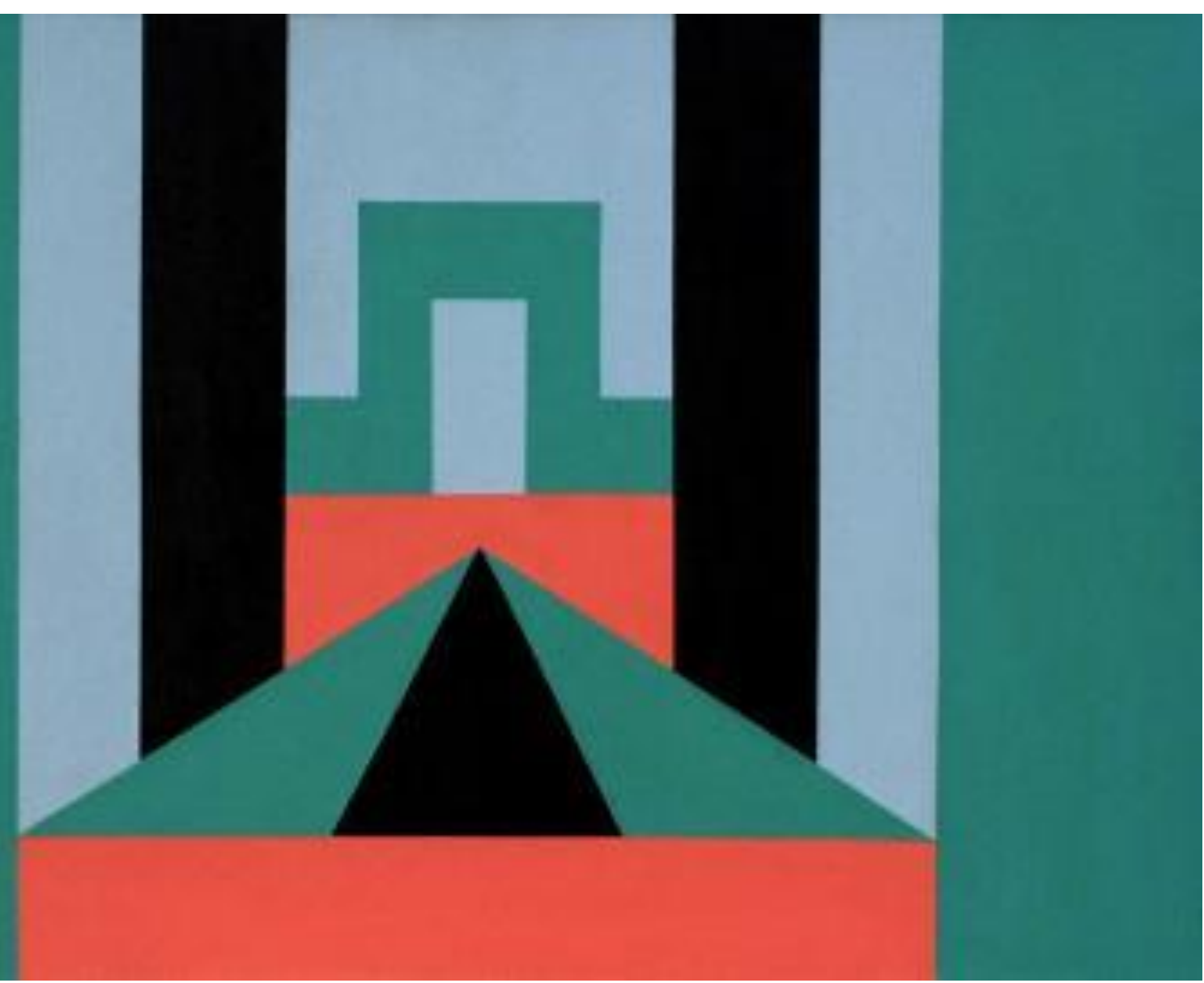

Uma dupla exclusão: Judith Lauand e Jandyra Waters, entre concretismos, misticismos e possíveis feminismos

A double exclusion: Judith Lauand and Jandyra Waters, between concretism, mysticisms and possible feminisms

\title{
Talita Trizoli
}

Como citar:

TRIZOLI, T. Uma dupla exclusão: Judith Lauand e Jandyra Waters, entre concretismos, misticismos e possiveis feminismos. MODOS: Revista de História da Arte, Campinas, SP, v. 5, n. 1, p. 231-248, 2021. DOI: 10.20396/modos.v5i1.8663977. Disponível em: $<$ https://periodicos.sbu.unicamp.br/ojs/index.php/mod/article/view/86 63977>. 


\title{
Uma dupla exclusão: Judith Lauand e Jandyra Waters, entre concretismos, misticismos e possíveis feminismos
}

\author{
A double exclusion: Judith Lauand and Jandyra Waters, between \\ concretism, mysticisms and possible feminisms
}

Talita Trizoli*

\begin{abstract}
Resumo
As narrativas já institucionalizadas sobre o movimento concretista no Brasil e suas reverberações abrangem referências internacionais para os artistas integrantes do movimento, e os conflitos de hegemonia cultural entre os dois polos econômicos do país na época: Rio de Janeiro e São Paulo. A considerável produção analítica sobre o período e seus agentes tem sido uma das mais férteis dentro da historiografia da arte brasileira, abarcando críticos, manifestos, obras, artistas e locais de circulação - e no entanto, apenas recentemente alguns pesquisadores e curadores têm apontado o caráter machista de alguns membros dos grupos, e as dificuldade de consolidação profissional das artistas mulheres que participavam dos projetos e reuniões. Nesse sentido, Judith Lauand, a única artista mulher a participar oficialmente do grupo Ruptura em São Paulo, é caso emblemático dos movimentos de revisionismo histórico feminista, mas junto a ela temos também Jandyra Waters ocupando um lugar ainda frágil no sistema, sem o devido cotejamento. Ainda que essas duas artistas tenham tido uma circulação considerável no meio artístico brasileiro, sua recepção crítica e inserção histórica não é a mesma de seus pares masculino, portanto, são casos que precisam ser revisitados a fim de esgarçar a malha historiográfica.
\end{abstract}

\section{Palavras-chave}

Arte concreta. Concretismo. Mulheres artistas. Misticismo. Feminismo.

\begin{abstract}
The already institutionalized narratives about the concrete movement in Brazil and its reverberations include international references for the artists who were part of the movement, and the conflicts of cultural hegemony between the two economic poles of the country at the time: Rio de Janeiro and São Paulo. The considerable analytical production about the period and its agents has been one of the most fertile within the historiography of Brazilian art, encompassing critics, manifestos, works, artists and places of circulation - and yet, only recently have some researchers and curators pointed out the sexism of some members of the groups, and the difficulties of professional consolidation of the female artists who participated in the projects and meetings. In this sense, Judith Lauand, the only female artist to officially participate in the group Ruptura in São Paulo, is emblematic of the feminist historical revisionist movements, but next to her, we also have Jandyra Waters occupying a still fragile place in the system, without due integration. Although these two artists have had a considerable circulation in the Brazilian artistic milieu, their critical reception and historical insertion is not the same as that of their male peers, therefore, they are cases that need to be revisited in order to tear the historiographic mesh.
\end{abstract}

\section{Keywords}

Concrete art. Concretism. Women artists. Mysticism. Feminism. 


\section{Premissas de análise}

É possível asseverar logo de antemão que, dentre os movimentos artísticos brasileiros já consolidados em nossa narrativa oficial historiográfica, o Concretismo, e sua relação no mínimo conturbada de parceria/paternalidade com o Neoconcreto, é território de uma das maiores disputas narrativas pela hegemonia de uma arte de vanguarda no transcorrer das décadas de 1950 e 1960.

A condição de assertiva, e não de possibilidade sobre essa querela, se dá justamente pela constatação de que, ainda que no seio da historiografia da cena artística brasileira e nos recentes esforços de revisão e de resgate de trajetórias e propostas estéticas seja possível verificar a existência de outros conflitos de natureza formal e política que tomaram de sobressalto o cenário das artes via estratégias midiáticas, pouco se compara à virulência ${ }^{1}$ nas argumentações de defesa entre os agentes artísticos no calor da hora, os partidos estéticos de seus analistas, e mesmo a recepção desigual desses movimentos no cenário artístico internacional mais recente.

No entanto, o que nos interessa nesse percurso de análise não é tanto o "ping-pong" hegemônico entre os grupos de São Paulo e Rio de Janeiro, ou a discussão sobre qual dos dois melhor representa e captura a anacrônica ideia de um "espírito do tempo" do projeto moderno nacional. São todavia pertinentes aqui as tentativas de consolidação do Concretismo como linguagem dominante durante 0 pós-guerra, seus conflitos e contradições formais e programáticos que permitiram o rechaço e exclusão de agentes hoje consideradas incontornáveis para uma constituição apurada da historiografia da arte do período, e que em alguma medida ajudam a compreender a ruptura neoconcreta deflagrada por agentes como Lygia Clark (1920-1988), Lygia Pape (1927-2004), Hélio Oiticica (1937-1980), Mario Pedrosa (1900-1981) e Ferreira Gullar (1930-2016).

No caso, refiro-me aqui a presença de duas artistas mulheres, que, de maneiras específicas, integraram e incorporaram as premissas do movimento Concreto, mas também delas se afastam: Judith Lauand (1922), única mulher a integrar o grupo e Jandyra Waters (1921), que adere tardiamente ao vocabulário geometrizado e insere aspectos místicos nas composições. Nesse texto, além de apresentar a produção de ênfase concreta dessas duas artistas, serão salientados certos aspectos dessas poéticas que contribuíram para sua dificuldade de adesão aos processos de consagração das narrativas oficiais da história da arte brasileira.

\section{Dos concretismos eletivos e seus percursos}

Existe certa concordância no meio historiográfico da arte brasileira que o evento artístico de caráter concreto com maior consolidação narrativa na cena local é a criação do Grupo Ruptura (GR) em São Paulo no ano de 1952, sobre a égide de Waldemar Cordeiro (1925-1973), seguido de seu desdobramento carioca no Grupo Frente (GF) em 1954, tendo aí Ivan Serpa (1923-1973) como aglutinador entre os artistas, e Mário Pedrosa e Ferreira Gullar como articuladores intelectuais ${ }^{2}$ - ainda que a entrada de tais questões em território nacional não tenha acontecido inicialmente com 0 desenvolvimento desses grupos, mas sim via publicações da época, como o Suplemento Dominical do Jornal do Brasil e a revista Arte \& Decoração, e via exposições tanto no Rio de Janeiro quanto em São Paulo (Varela, 2017)3. Assim, constata-se que os GR e GF são marcos históricos mais por sua capacidade de divulgação das questões concretas $^{4}$, do que por ineditismo do tema em território nacional.

A ideia de uma arte concreta brasileira toma então corpo no meio artístico a partir de leituras e interpretações peculiares sobre as vanguardas de caráter geometrizante que se espalharam pelo 
território europeu - e ressalta-se aqui o caráter particular dessas interpretações em todo o espectro latino-americano, principalmente na Argentina e Uruguai, pois ocorre uma seletiva de preceitos e programas estéticos a fim de valorizar um determinado projeto de modernidade, ou seja, um devir de mundo pautado pela ideia de progresso, desenvolvimento industrial e alto investimento na lógica do capital, em detrimento de perspectivas críticas às modalidades de vida ocidental, e para dizer em outros termos por fim, da vertente espiritualista e reencantatória da modernidade.

Assim, creio ser pertinente retomar de modo breve alguns aspectos pontuais das formações concretas na cena europeia e latino-americana, a fim de compreender os partidos estéticos de GR, e as dificuldades de adesão de Lauand e Waters nessa grande narrativa concreta nacional.

Desse modo, partindo de manifestos, artigos e ensaios de Cordeiro ${ }^{5}$, Pedrosa (1996: 258) e Gullar (1959: 04-05), é possível verificar que as agrupações artísticas elegidas como referencial teórico e plástico para a cena artística brasileira são tanto o grupo holandês De Stijl quanto as ditas vanguardas russas - sendo que Max Bill ocupa a égide de herói individual ${ }^{6}$ nesses relatos da história concreta brasileira, como um último bastião dos preceitos modernos do gênero ${ }^{7}$.

O grupo De Stijl e seu projeto estético fazem parte de um fluxo racionalizante e utópico no meio artístico que cruzava os principais centros culturais europeus no entreguerras, e tinha como um de seus motes o desvinculo da prática artística e seus produtos da égide romântica de certas vertentes estéticas. Dentre seus pares revolucionários constam o Construtivismo russo e o Suprematismo - ainda que sem o atravessamento marxista que complementa esses dois últimos - e as investigações formais cubistas e abstratas de Wassily Kandinsky (1866-1944). Em síntese, os artistas do grupo De Stijl, dentre eles Theo van Doesburg (1883-1931), Piet Mondrian (1872-1944) e Georges Vantorgerloo (1886-1965) como nomes mais representativos, propunham a busca por uma fatura artística de caráter abstrato, em detrimento dos códigos de representação figurativa que imperaram por séculos, por acreditarem em um processo evolutivo do mundo - e consequentemente do universo das artes - em direção a um território de racionalidade e elevação moral e espiritual, com um vocabulário visual abstrato e universal. Vide alguns excertos da primeira edição da revista de 1917, com alguns destaques sublinhados que asseveram essa postura:

\footnotetext{
O objetivo deste pequeno periódico é contribuir com algo para o desenvolvimento de um novo sentido de beleza. Pretende sensibilizar o homem moderno para as novas ideias que surgiram nas artes plásticas. Quer estabelecer os princípios lógicos de um estilo de amadurecimento que assenta numa relação mais clara entre o espírito da época e os meios de expressão, contra a confusão arcaica, o "barroco moderno".

(...) Assim que os artistas dos vários ramos da arte plástica perceberem que devem falar uma linguagem universal, não mais se agarrarão à sua individualidade com tanta ansiedade. (...) A propagação da beleza requer uma comunhão espiritual e não social. Uma comunhão espiritual, entretanto, não pode ser realizada sem sacrificar a individualidade ambiciosa (Jaffé, 1956: 11). ${ }^{8}$
}

Talvez em nossa concepção de racionalidade pautada por um referencial tecnocrata e científico eurocentrado soe estranho essa conjunção entre uma modernidade racional e universalista junto a preceitos espiritualistas e transcendentais da mundanidade, no entanto, tal convergência era um lugar comum entre os atravessamentos teóricos modernos, em que a ciência como um campo de episteme e veridicção já bem alocado, passava por um processo de reformulação metodológica. Isso vai ao encontro a uma busca generalizada por outras possibilidades construtivas de mundo 9 . 
Ainda sobre o grupo De Stijl, vale lembrar aqui o vínculo e admiração estabelecidos por Mondrian ao fundar o Neoplasticismo, desdobramento do grupo holandês, junto a Teosofia moderna da mística Madame Blavatsky ${ }^{10}$ (1831-1891), e as convergências do uruguaio Joaquín Torres-García (1874-1949) com o universalismo concretista e a identidade latino-americana convertida em exotismo fantástico pelo olhar eurocêntrico ${ }^{11}$.

No caso de Mondrian-Blavatsky sucede um debruçamento sobre narrativas antigas e práticas religiosas ancestrais, que passam pelo hinduísmo, neoplatonismo até a cabala judaica, e que para além de um corpo dogmático religioso, mostrava-se como uma articulação sincrética de entendimento do mundo via a experiência mística - mas uma experiência fundamentada em uma ordenação, em um regramento dos mistérios, que se manifesta geometricamente, portanto, hierarquicamente, e que toma de empréstimo concepções da ciência dita moderna para sua validação pública ${ }^{12}$.

Essa relação no mínimo curiosa entre a produção artística de vanguarda e a teosofia já foi explorada por algumas investigações acadêmicas (Ringbom, 1966: 386-418; Henderson, 1984: 205-210), demonstrando como o vínculo entre a busca por novos programas de vida ia ao encontro das formulações de investigação do real para além das explanações racionais e consolidadas pela ciência ${ }^{13}$ - aspecto esse mobilizado por Waters em suas obras, e em menor escala, por Lauand, como veremos mais adiante.

Já no caso do uruguaio Joaquín Torres-García, o caráter polifacético de sua produção e trajetória oferece alguns índices interessantes de conexão entre a fascinação mística do vocabulário concreto e as particularidades simbólicas latino-americanas. Conhecido como um exímio diplomata estético entre os protocolos artísticos dos grandes centros, no caso o circuito de agentes da arte em Paris, e a contingência latino-americana e sua condição de cultura colonizada (algo que 0 artista apenas contempla em seu período de maturidade, quando retorna a Montevideo após se mudar com a família aos 16 anos de idade), Torres-García é um caso paradigmático da miscelânea moderna entre valores estéticos de vanguarda já consolidados e as especificidades geográfico-históricas do hemisfério sul ${ }^{14}$. Sua concepção de arte concreta vai ao encontro de uma dimensão sensivel das formas, a um vocabulário universal de transcendência, que se afasta justamente da perspectiva hiper-racionalizada e científica que paira no imaginário das vertentes concretas - algo que reverberará tardiamente na cena brasileira ${ }^{15}$, principalmente com o choque da individual do artista consumida pelo fogo do incêndio do MAM RJ em 1978. Torres-García, ao elaborar seus ensaios sobre o caráter universal e sensível do construtivismo, afirma ainda na década de 1930:

Há uma ordem universal interna, abstrata, que terá sua fundação no nosso mais profundo, corresponderá a outra ordem objetiva, tão absoluta, que será o concreto dos elementos materiais. E esse milagre da fusão entre matéria e espírito é o que realiza o artista, o poeta, o músico e 0 arquiteto (Torres-García, 2000: 84).

Com seu cosmopolitismo regionalista, Torres-García almejava efetuar uma juntada entre os preceitos estéticos do De Stijl com as especifidades de uma identidade latino-americana ligada a questões místicas, religiosas e mitológicas, algo que ressoou, e ainda ressoa em diversos ouvidos, ora como uma deturpação da pureza universalista euro-concreta, ora como uma submissão colonizada à lógica dominante.

Tendo em consideração essas duas referências de tão importante impacto em nossa cena artística, que lidam justamente com uma vertente reencantatória da vida via o escopo estético concreto, chega a ser no mínimo curioso verificar como os intérpretes críticos no calor da hora (e mesmo posteriores à 
deflagração dos preceitos concretos em território latino-americano ${ }^{16}$ ), efetuam um malabarismo retórico a fim de borrar essas referências místicas e higienizar racionalmente essas fontes, a fim de valorizar 0 projeto moderno e progressista de nação.

A leitura efetuada por Cordeiro sobre essas vanguardas por exemplo, oblitera o caráter místico dessas ações e as converge com as questões gramscianas, elegendo então como segundo movimento de interlocução formal os concretos russos, mas também com uma leitura acidentalmente enviesada desses agentes ${ }^{17}$. Mesmo os intérpretes posteriores, como Ronaldo Brito (1951) ${ }^{18}$, Aracy Amaral $(1930)^{19} \mathrm{e}$ até mesmo Roberto Pontual $(1939-1994)^{20}$ com sua geometria sensível, não acessam essa dimensão transcendental das vanguardas geometrizantes, preferindo um referencial pautado pela racionalidade progressista e industrial que supostamente fundaria nossa arte moderna - e é justamente nesse ponto que reside parte das práticas de apagamento da produção de Lauand e Waters, juntamente à condição de gênero "frágil" dessas agentes.

\section{Modelos de feminilidade e a práxis artísticas de Lauand e Waters}

Nos idos da década de 1950, em meio ao frenesi do boom industrial que pairava sobre as cidades de São Paulo e Rio de Janeiro no início dessa década, sendo a primeira uma auto-projeção de locomotiva econômica-nacional, e a segunda a capital político-cultural do país, que aos poucos perdia essa hegemonia para o território paulista e para a criação da cidade de Brasília em 1960, o modelo de feminilidade que perpassava o imaginário coletivo brasileiro oscilava entre alguns estereótipos de conformação ao desejo masculino e de família nuclear, e por vezes resvalava em tipos femininos sedutores e joviais, de enfrentamento das normas conservadoras de subjetivação, mas que recaíam nesse imaginário numa condição de degeneração social da mulher.

Os processos de subjetivação do feminino nos chamados "anos dourados" tinham como principal regência as peças jornalísticas de revistas femininas, as quais repercutiam e reforçavam discursivamente modelos de feminilidade tradicionais e coaptados pelo desejo masculino. Assim, arquétipos sociais como os da namoradinha, noiva e esposa ideais, emuladores de uma maternagem conformista, ocupavam uma ponta do espectro idealizado da feminilidade, enquanto que em outra ponta residiam as mulheres infiéis, inférteis por condições biológicas/sociais, ou rebeldes socialmente, como profissionais, intelectuais, solteironas, desquitadas ou lésbicas, sinônimos de desordem do pacto social patriarcal.

As distinções em termos de valorização social criam uma hierarquia entre as próprias mulheres: as "moças de família" (ou "boas moças') estão acima das "levianas"; e as prostitutas ocupam o grau inferior nessa escala de respeitabilidade. Tachar uma moça de "leviana", torná-la "mal falada", acaba sendo uma forma de marginalizar o que é diferente, o que foge à regra. Pois a moral que estabelece o "comportamento correto" não pode ser contestada e o estigma - baseado em transgressões reais ou apenas em fofocas maldosas - acaba sendo algo socialmente necessário para a manutenção da ordem...

Um comportamento feminino desviante (ou "desviado" por alguém) ameaça a honra familiar, a moral estabelecida e, finalmente, as próprias relacõos de gênero justificadas por esta (Pinsky, 2014: 124-125).

É dentro desse espectro moralizante, de controle dos corpos e dos desejos femininos que Lauand e Waters se lançam como artistas em busca de consagração, e negociam sua performatização de feminilidade em concomitância às eletivas temático-formais de seus trabalhos artísticos.

Comecemos por Judith Lauand. Nascida em 1922 na cidade de Pontal, no interior paulista, mas com grande parte da infância passada na cidade de Araraquara, onde primeiramente estuda pintura na Escola de Belas Artes local e recebe um treinamento pictórico com vocabulário realista e expressionista, 
a artista efetua uma virada formal em sua produção quando muda-se com a família para São Paulo em 1952.

Nesse mesmo ano, participa de uma exposição coletiva ligada à sua antiga instituição de formação, e recebe atenção positiva da crítica, que resulta em uma individual em 1954 na Galeria Ambiente. Com uma inserção ainda pontual no circuito, é ainda nesse ano, quando atua como monitora voluntária na II Bienal de São Paulo e tem contato com as vanguardas artísticas europeias ${ }^{21}$, juntamente às primeiras trocas com membros do GR, que Lauand efetivamente toma o vocabulário abstrato-geométrico como norte em suas obras. Mas o convite para participar do GR surge apenas após o contato de Cordeiro com a obra de Lauand durante o $4^{\text {a }}$ Salão Paulista de Arte Moderna na Galeria Prestes Maia em 1955, evento onde ela divide a cena com outros membros do GR. Assim, em concomitância a também entrada do jovem Maurício Nogueira Lima (1930-1999), Lauand é oficialmente inserida no círculo concretista de São Paulo em 1955.

As relações então estabelecidas dentro do grupo, no que diz respeito a Lauand e seus colegas homens, são dúbias: por um lado, em entrevistas e declarações, a artista aponta o acolhimento profissional realizado pelos colegas e certa neutralidade de tratamento quanto a seu gênero:

Embora Lauand não tenha sido um membro fundador (oficialmente ingressando em 1955), a evolução de sua carreira foi significativamente enquadrada como um privilégio e uma anomalia no contexto de seu status como membro do grupo masculino. No entanto, sobre o relacionamento com os colegas do sexo masculino, Lauand disse recentemente: "Não me sentia mulher, me sentia um ser humano" (Edelman; Driscoll, 2014: 09).

Mas em outras ocasiões, o sexismo que atravessa ao largo toda a cultura brasileira se manifesta, nas divisões de tarefas das empreitadas dos membros, nas críticas formais emitidas ao trabalho de Lauand e, posteriormente, nas dificuldades de aderência de sua obra na grande narrativa da arte concreta do Brasil.

Sobre a fortuna crítica de Lauand, note-se aqui pelo menos duas referências nas quais a adjetivação do julgamento faz uso de termos ligados à feminilidade - mas que em nada correspondem à natureza formal das obras: a definição do trabalho de Lauand por Ana Maria Belluzzo como "geometria feminina" (Belluzzo, 1998: 130) e a constância de Paulo Herkenhoff (1949) em classificar sua obra como um conjunto de "tensões delicadas". Atentemos ao seguinte fragmento desse ensaio de Herkenhoff, que após uma explanação respeitável sobre os embrenhamentos compositivos e investigações formais dos trabalhos da artista, conclui que "Judith Lauand buscava alguma razão matemática, mas sobretudo também muitas licenças poéticas. Daí podemos dizer que Judith Lauand produziu uma arte de pequenas delicadezas concretistas" (Herkenhoff, 1996: s/p).

Mas a partir dessa assertiva final de Herkenhoff permanecem algumas indagações complexas: o que caracteriza uma "tensão delicada" ou uma "delicadeza concretista" numa estrutura compositiva pautada por preceitos matemáticos? Como determinar uma forma delicada ou feminina? É apenas em relação a uma forma rústica ou masculina que podemos constatar a existência de um equivalente-oposto feminino? É possível delimitar gênero às formas? Bem, a reposta para essa série de indagações seria confirmativa apenas se fosse possivel entendermos a forma como um símbolo, como extensão discursiva de uma ideia, o que não é o caso da produção concreta brasileira, que procura justamente trabalhar com a concepção de forma sem sedimentações culturais, sem significado - portanto, a conclusão de Herkenhoff sobre o trabalho de Lauand se mostra anacrônica, além de sexista. Em 
entrevista a Camila Molina, Lauand comenta sobre essa adjetivação "sensível" que persiste em sua produção:

"Isso vai da sensibilidade de cada artista, cada um resolve os problemas da obra à sua maneira. Acho que todos do grupo faziam um concretismo sensivel, não havia diferença entre nós. O Fiaminghi tinha uma pesquisa de formas e, principalmente, de cor, das mais sensiveis", diz Judith. (Molina, 2007: s/p).

Mas talvez o episódio mais evidente dessa dualidade de relações seja no período em que membros do GR, já um tanto distanciados dos preceitos dogmáticos de Cordeiro em relação aos protocolos compositivos, passam a perlaborar questões da abstração lírica e da pop art que tomavam de assalto a produção artística da época, e em concomitância às tentativas de solidificação de um mercado de arte frágil e instável, criam uma galeria de arte com gerência coletiva, a Galeria Novas Tendências, em 1963. Se, nessa ocasião, Lauand já não era mais a única mulher integrante do grupo de artistas, já que Mona Gorovitz (1937) também participava das atividades na condição de artista, mas também de parceira amorosa de Cordeiro, a divisão de tarefas e de cuidado com a galeria obedecia a uma ordem sexista de organização, como fica claro no depoimento de Lauand ao jornalista Celso Fioravante (1962):

Nós não conseguíamos expor em nenhum lugar, então decidimos criar uma galeria nossa. Mas não deu certo. Cada artista deu um quadro para que fosse vendido para pagar aluguel e manutenção... A galeria não aguentou muito tempo. Mas foi uma experiência válida. Eu vendia os meus quadros lá, poucos, poucos mesmo, mas o Waldemar Cordeiro achava que eu deveria vender os dele e de todos os colegas. Mas eu não tinha muito jeito pra vendas (Fioravante, 2011: 10).

Infelizmente, esse tratamento diferenciado por parte de Cordeiro para com Lauand não era de modo algum a única experiência de caráter sexista dispendida à artista - a época era propícia a paternalismos e desqualificações machistas, o que obrigava as mulheres a uma constante negociação de narrativas, performatizações de gênero e estratagemas de manifestações do desejo. Por ter optado muito jovem por uma vida como artista, buscando acima de tudo profissionalização e reconhecimento laboral, Lauand nunca se casou, ainda que tenha tido relações amorosas ao longo da vida. Assim, a opção pela identidade profissional em detrimento de uma identidade como esposa de família nuclear gerava incômodos no âmbito familiar, a ponto de a artista fazer uso de um anel como aliança ao longo de meses, para evitar cobranças paternas e maternas quanto ao término de seu noivado (Fioravante apud Edelman, 2014: 19). Ao ser indagada sobre sua solteirice e se sentia falta de uma família, a artista assevera: "Eu me casei com a arte. As pinturas são minhas crianças" (apud Toso, 2011: s/p).

Mas ainda que haja essas complicações de ordem social e de performatização da feminilidade, que em certa medida dificultam a inserção da produção de Lauand na grande narrativa concreta brasileira, já que nosso corpo historiográfico artístico é ainda permeado por critérios de valor e protocolos de juízo pautados por mitos de autonomia, qualidade e inovação, há um outro aspecto de caráter formal, dentro da própria lógica operativa dos preceitos concretos que também dificultam uma plena aderência de Lauand a essa esfera de consagração, e que se estende também para a produção de Waters que veremos mais adiante: sua palheta cromática.

Relembremos aqui que, de acordo com as assertivas de Cordeiro sobre as diretrizes válidas para a produção da nova arte concreta, a presença da cor é uma condição estrutural equivalente aos demais elementos compositivos da obra, como linhas e planos, e sendo ela unidade/elemento compositivo e não mais artifício ilusionístico, ela articula relações, mais do que formas, de acordo com sua posição e 
dimensão. Crítico dos malabarismos retóricos pictóricos que, em sua perspectiva estética, resvalavam em superficialidades que nublam a natureza e potência do fenômeno artístico, Cordeiro utilizará justamente esse aspecto plástico como munição para a crítica de seus colegas cariocas, que já se inclinavam para o espírito neoconcreto - e a crítica mais icônica reside na suposta displicência cromática de Ivan Serpa com seus marrons ${ }^{22}$.

0 dogmatismo formalista de Cordeiro bebe em diversas fontes modernas, principalmente o neoplasticismo de Mondrian e de seus colegas do De Stijl, e ainda que inicialmente esse tenha sido o protocolo cromático apresentado a (e se seguido por) Lauand, eventualmente a artista afasta-se dessas interdições pictóricas, e toma Joseph Albers, com que teve contato durante a IV Bienal em 1957, e seus "manuais" como referencial de experimentação da $\operatorname{cor}^{23}$ - será tal gesto que produzirá ruídos nas correlações críticas entre a produção de Lauand e a produção de seus colegas do GR.

Nessas telas da artista, estruturadas via um jogo de elipses e de centrífugos/centrípetos, que denunciam seu apreço pela nomenclatura da perspectiva, além de seriações geométricas de triângulos, losangos e octógonos juntamente a linhas curvas ou retilíneas, sobrepostas, convergentes e paralelas, engrossadas por uma calculada concentração de cor, propiciam a construção de um ritmo, um movimento compassado dessas formas que levam o olhar do observador por um percurso espiralado na planaridade da tela.

Tomemos como exemplo de uma primeira análise Do círculo ao Oval de 1958 [Fig. 03]. A dinâmica simétrica instaurada pelos triângulos angulosos formados por uma fina linha esverdeada, que reverbera sobre pontos marcados sobre a superfície amarela ácida da tela, efetua uma repetição gradativa dessas formas em torno de um eixo circular ${ }^{24}$, e permite a construção de uma forma estelar com proporcionalidade referencial à sequência de Fibonacci, solução essa bastante recorrente nas produções do GR.

Ainda que tal composição faça coro a toda uma série elaborada por Waldemar Cordeiro ao longo da década de 1950, intitulada Ideia Visível, a particularidade cromática de Lauand contrasta fortemente com a programação pictórica de Cordeiro: enquanto Waldemar opta por uma economia de cores (no caso vermelho, preto e branco que se revezam entre linhas e fundos chapados, com uma eventual exceção a um amarelo dourado, presente como fundo na tela Movimento Ruptura de 1952), Lauand, em sua peça, faz uso estratégico da vibração cromática de contraste dinâmico entre o amarelo ácido e o verde como recurso para potencializar a movimentação centrífuga da forma estelar, que parece ascender para o canto esquerdo superior do quadro.

Essa estratégia de correlação entre as capacidades dinâmicas do contraste cromático com as formas geométricas é um recurso bastante mobilizado por Lauand, ocorrendo também na tela Espaço Virtual de 1960 [Fig. 5] e Sem Título, de 1955 [Fig. 4]: ambas apresentam uma estrutura compositiva centralizada, de plena ocupação da superfície quadrangular da tela, e, tanto pelo uso de repetições seriadas de triângulos, trapézios e retângulos de lados desproporcionais quanto pela aplicabilidade de cores contrastantes (e ligeiramente distantes da palheta oficial de Cordeiro na época), Lauand consegue estabelecer um marco autoral em seus jogos compositivos geométricos, aproximando-se inclusive dos vocabulários geométricos transcendentais ${ }^{25}$, rejeitados pelos primeiros interlocutores locais das vertentes construtivas. 
Em ambas as telas, as formas geométricas convertem suas polaridades em direção ao núcleo da composição, indicando assim um movimento vertiginoso de mergulho em um centro abissal. Espaço Virtual apresenta uma estrutura mais harmônica, com os formatos geométricos proporcionais entre si, construídos com linhas finas entre um branco luminoso e um azul e rosa vibrante que saltam do fundo preto homogêneo como uma dança circular. Já a tela de 1955, reproduzida na Fig. 4, estabelece um movimento de caída vertiginosa, orquestrada tanto pela disposição compositiva de retângulos, trapézios e retângulos irregulares na cor preta, e grossas linhas de perspectiva num verde acinzentado.
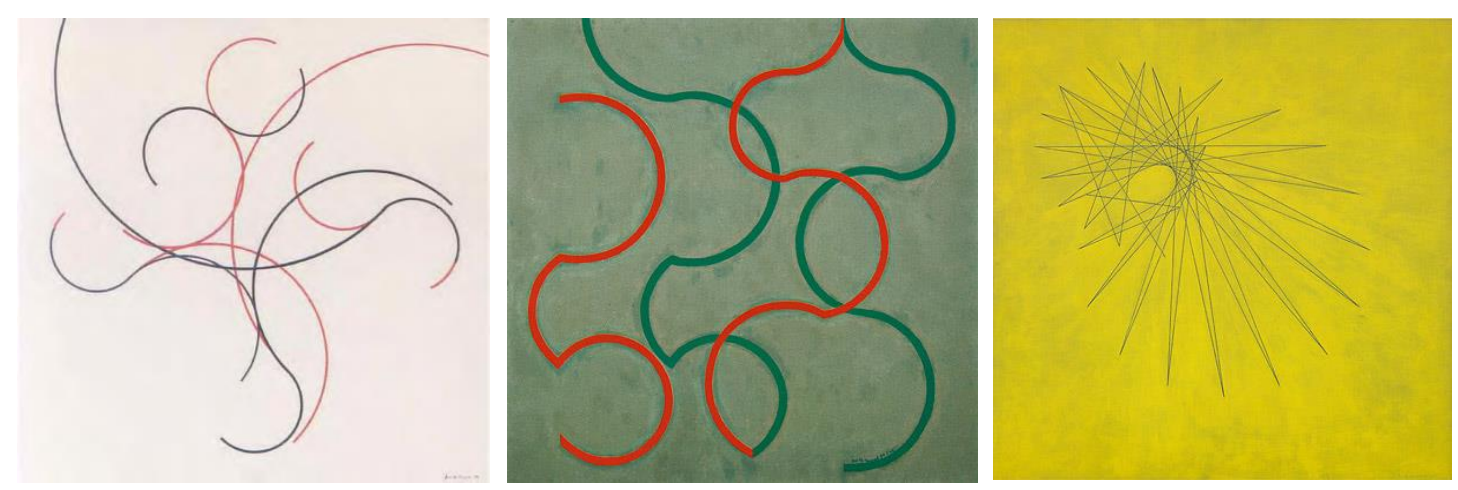

Fig. 1. Judith Lauand,.C40, Variação com curvas, 1956. Fonte: Fioravante, 2011: 21. Fig. 2. Judith Lauand. C42, 1956. Fonte: Fioravante, 2011: 21. Fig. 3. Judith Lauand. Do círculo ao Oval, 1958. Fonte: Edelman; Driscoll, 2017: 24.
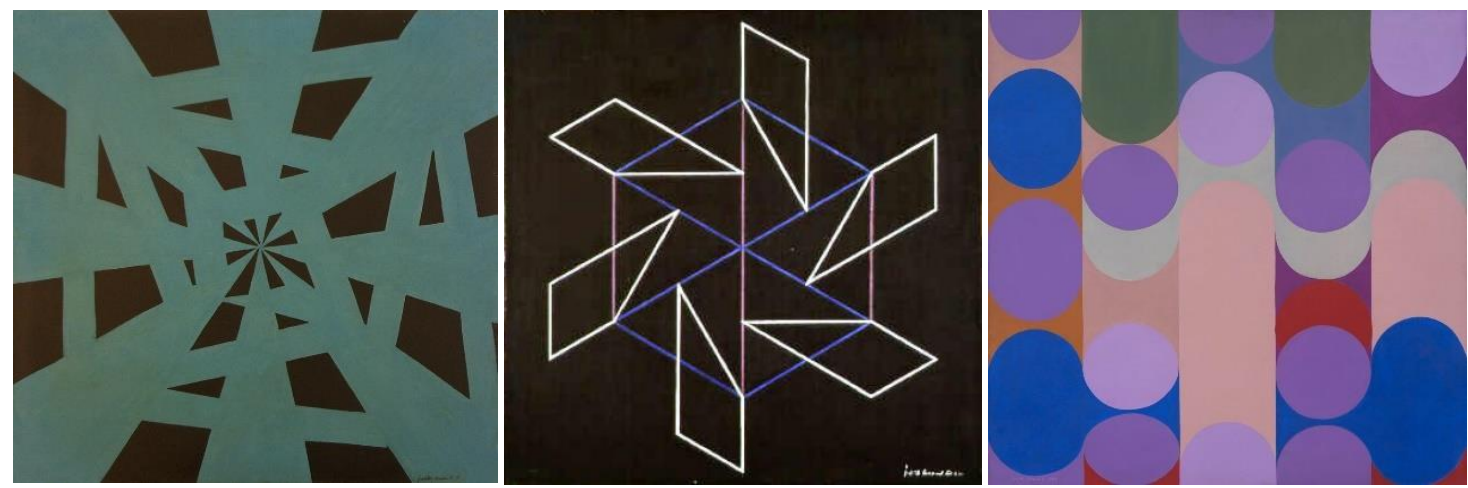

Fig. 4.Judith Lauand. Sem título, 1955. Fonte: Fioravante, 2011: 20. Fig. 5. Judith Lauand. Espaço virtual, 1960. Acervo/Fonte: MAC/USP. Fig. 6. Judith Lauand. Sem título, 1967. Fonte: Fioravante, 2011: 47.

O dinamismo das formas sobre a superfície pictórica é um recurso sistemático nas composições de Lauand, e ainda que haja indicativos de uma preferência da artista pela linearidade da perspectiva e sua capacidade de criação de um vórtice do olhar, ela faz também uso das desproporcionalidades compositivas a fim de salientar um ritmo e um dinamismo geométrico. Em C40 Variação com Curvas [Fig. 1] e C42 [Fig. 2], ambas de 1956, chama a tenção o uso de elipses fragmentadas, quebradas e sobrepostas, que ora estabelecem um ponto de convergência não-harmônico na planaridade da tela, ora efetuam uma cooptação da intensidade das forças das linhas circulares e suas quebras e desvios - C40 ainda dá indicativos de um impulso de centralização, de uma concentração das linhas em uma 
área específica, já C42 parece abdicar disso em prol de uma cadência rítmica dessas linhas, intensificada pela sua espessura e pelas cores verde e vermelho sobre o fundo verde-acinzentado.

Atentemos mais uma vez para a escolha cromática de Lauand nessas composições, que se afasta do conjunto de cores de Cordeiro: verde, vermelho e branco em nada indicam uma economia simplória de palheta, mas sim uma preferência pelos contrastes ácidos, como podemos verificar no último exemplo da artista nesse ensaio, a obra Sem Título, de 1967 [Fig. 6], em que a construção de uma padronagem próxima à lógica de uma estamparia psicodélica e pop transita entre os tópicos investigativos da artista de base concreta e sua breve incursão no figurativismo pop-cinematográfico da década de 1960. Nessa obra de 1967, novamente vemos o uso de um dinamismo de esferas e elipses que estabelecem um movimento de subida e descida ao longo da tela, potencializados pelo uso de verdes, lilases, rosas, azuis e vermelhos, formando assim um conjunto que se distancia profundamente das diretrizes pictóricas estabelecidas pelo GR e sua liderança.

Mesmo quando Lauand segue experimentando pontualmente materiais de ênfase pop ou de plasticidade povera, mantêm-se essa noção imperativa de um ritmo cadenciado e dinâmico das formas. Nesse sentido, sua produção permanece no espectro protocolar do concretismo paulista, e é então na cor que ocorre sua revolução e sua ruptura parcial com o dogma concreto.

Já no caso de Jandyra Waters, temos muitas similitudes com a trajetória de Lauand, mas também diferenças. Nascida em Sertãozinho em 1921, Waters também se muda cedo com a família para São Paulo, onde obtêm uma formação profissional de secretariado e estuda línguas na Cultura Inglesa. Bilíngue, a jovem logo se cadastra na UNRRA (Administração das Nações Unidas para Assistência e Reabilitação) e viaja em 1945 para a Inglaterra a fim de auxiliar os processos de recuperação da Segunda Guerra Mundial. Ali conhece seu marido, Eric Dale Waters, um major médico, com quem se casa em 1947 e tem um único filho, Martin. Nesse mesmo ano, fixa residência em Lewes, Sussex, e estuda no Country Council Art School por cerca de um ano, até desenvolver alergia às tintas durante 0 período de gestação e se afastar do ateliê. Martin nasce em 1949, e a família decide mudar-se para 0 Brasil em 1951, onde Waters retoma os estudos em pintura com Yoshiya Takaoka (1909-1978) e Clóvis Graciano (1907-1988), entre outros.

Do mesmo modo que Lauand, Waters inicia sua produção pelo vocabulário figurativo e expressionista, que segue de naturezas mortas florais, capturas de cenas domésticas em vórtices e cantos da casa com objetos de índice da feminilidade, ou mesmo paisagens com vestígios bucólicos no urbano. Logo a artista abandona a figuração e passa a experimentar possibilidades abstratas das mais variadas: na década de 1960 produz o que se convencionou chamar de abstração lírica ou pulsional, para depois, em chave matissiana, mobilizar figuras orgânicas e amorfas construídas com cores vibrantes de forte contraste com fundos neutros e monocromáticos, as quais operam por uma lógica explosiva de movimentos na composição, como fica bem evidenciado na tela Sem Tíulo de 1967 [Fig. 7].

Ainda que seja interessantíssima a produção da década de 1960 da artista, e com a qual ela adquire circulação em espaços expositivos, diversos salões (inclusive a $9^{\mathrm{a}}$ Bienal de São Paulo em 1967 e a $2^{\text {a }}$ Bienal Nacional de Artes Plásticas da Bahia em 1968), e ela estabeleça trocas pontuais com a esfera da crítica de arte, nos interessa nesse momento sua segunda reviravolta abstrata, dos anos 1970, agora em direção à geometrização, onde permanecerá por anos - é nela que ocorre a convergência com a produção de Lauand, pela cor e em menor escala, pela espiritualidade. 
"Jandyra, com sua inteligência visual intuitiva, é uma artista construtiva, mas nunca concreta" (Mattar, 2015: 05). Essa assertiva da curadora Denise Mattar sintetiza tanto a relação problemática de aderência de Waters na narrativa concreta nacional quanto a interpretação dispendida a seu gênero: por um lado, a adesão tardia de Waters ao vocabulário geométrico e seus desafios compositivos condiciona 0 entendimento da produção da artista como algo anacrônico à época, derivativo, e, por outro lado, Waters, do mesmo modo que Lauand, encontra-se à mercê de sexismos no julgamento estético de sua obra, como se fosse ela uma extensão intrínseca de seu marcador social de gênero.

O vínculo de Waters com o espectro concretista, ainda que em retardo, é relevante no sentido de ser a principal produção do gênero que não recua frente às conexões místicas de sua obra ${ }^{26}$. Enquanto os integrantes do GR pautavam sua produção e mesmo a recepção de suas obras numa perspectiva racionalizada da geometrização abstrata ${ }^{27}$. Waters sinaliza este vínculo e abraça o lado místico da modernidade construtiva. Theon Spanudis (1915-1986), seu principal interlocutor crítico, assevera inúmeras vezes isso - mas vejamos apenas um exemplo:

A mais inquieta, a mais explosiva dos novos construtivistas brasileiros. Seus trabalhos transmitem a complexidade dos movimentos que fogem do quadrado do quadro para nos dissolver em voos e vivencias cósmicas e por isto, religiosas. Um profundo misticismo que vibra dá o sabor todo especial e inconfundível da sua pintura (Spanudis, 1981: s/p).

Waters foi uma voraz consumidora de material espiritualista ao longo de sua vida, como aponta seu filho:

Ela em sua infância, nos anos 20 era católica como quase todos os habitantes de São Paulo, da época. Frequentar missa, rezar antes das refeições, quadro da Santa Ceia pendurado na sala de jantar da casa dos pais, etc. Mais tarde, não seguiu a religião católica e de fato ela não tem assim uma religião... tem fé ... se dedicou muito a estudos filosóficos (Rosa Cruz, Palas Athena, etc) e outros cursos livres de filosofia. Se interessou pela filosofia oriental, religião budista, dos hindus, etc... esteve na Índia e no Nepal em retiro para estudos numa localidade (acho que chama Mount Batten), perto de Nova Delhi, que é onde existem esses ensinamentos por mais ou menos um mês (Waters, $2020)^{28}$.

Essa miscelânea de referências na parte conceitual da fatura de Waters contrária aos preceitos concretistas toma corpo nas poucas unidades com titulação não-neutra, como as da fase dita "preto e branco" do final dos anos 1960, nos livros de poesia com ilustrações de sua autoria ${ }^{29}$, e em certas sugestões estruturais arquitetônicas presentes nas composições da década de 1970 em diante, seja nas pinturas, sua mídia predominante, seja nas pequenas esculturas/maquetes. "Jandyra Waters é uma revelação pela vibração das suas obras, pela tensão metafísica da sua obra, pela exploração que faz da simbologia esotérica: um construtivismo forte, uma pintura mágica" (Zago, 1980: 15).

Tomando aqui a sequência de telas Sem Título dos anos de 1977, 1978 e 1980, apresentada nesse texto, percebe-se a mobilização de sólidos geométricos com cores chapadas, dispostos na superfície pictórica como elementos de constituição arquitetônica - mas não tão vibrantes e contrastantes como as utilizada por Lauand, pois a palheta elegida por Waters resulta em composições pictóricas mais estáticas, sem grandes saltos de cor ao olho, como se a artista efetuasse um percurso telúrico pelos espectros cromáticos. 

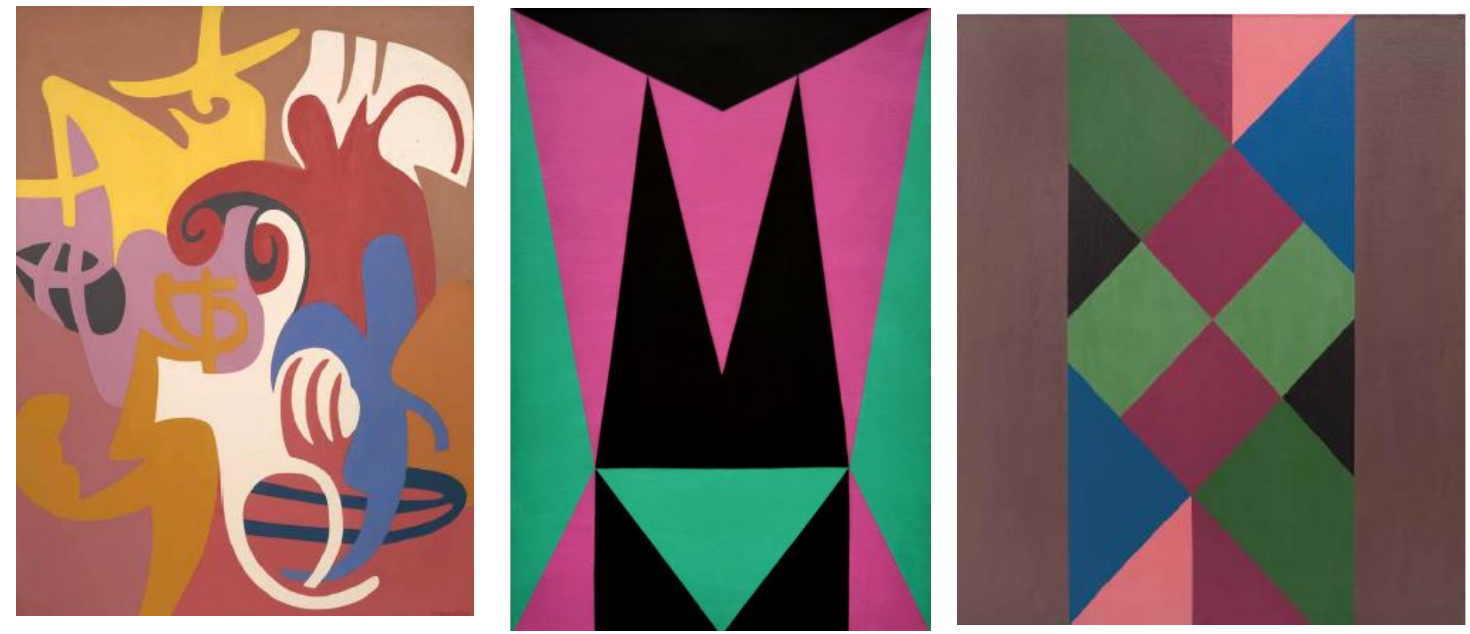

Fig. 7.Jandyra Waters. Sem Título, 1967. Fonte: Mattar, 2015: 14. Fig. 8. Jandyra Waters. Sem Titulo, 1980. Fonte: Mattar, 2015: 41. Fig. 9. Jandyra Waters. Sem Título, 1977. Fonte: Moraes, 2018: 09.
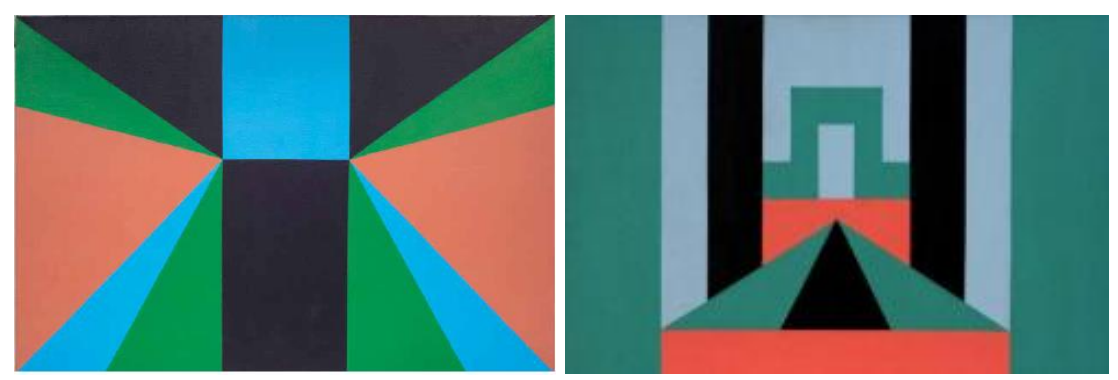

Fig. 10. Jandyra Waters. Templo, 1982. Fonte: Mattar, 2015: 63. Fig. 11. Jandyra Waters. Sem Título, 1978. Fonte: Mattar, 2015: 31. Fig. 12. Jandyra Waters. Sem Título, 1976. Acervo/Fonte: MAC/USP.

Nessas telas, a dimensão abstrata geométrica impera, com o uso sistemático de triângulos e retângulos num jogo compositivo de mandalas, dispositivos espiritualistas de transcendência da percepção, mas que faz também referência às configurações místicas, alquímicas e teosóficas de uso das formas geométricas como equivalentes matéricos e etéreos. Nesse arranjo mágico, as figuras correlacionam sua concretude formal às demais dimensões do cosmo, funcionando como signos de condensação das forças - um quadrado faz referência à unidade do mundo e à estabilidade dessas forças por sua condensação dos ditos pontos cardeais, sendo os triângulos as variantes dessas energias, indicando suas qualidades e dualidades, enquanto o círculo se relaciona com a percepção de completude e de forma originária para os demais sólidos (Pennick, 1980: 15-24).

Já na tela de 1976, também Sem Titulo, dois retângulos de um verde musgo emolduram a composição como pilastras que permitem o vislumbre de uma estrutura em perspectiva similar à entrada de uma nave de igreja ou de um templo religioso, como se uma janela ou porta se abrisse ao espectador e um caminho misterioso fosse revelado ao longo da contemplação. A mobilização de uma sugestionabilidade 
arquitetônica nas composições geométrico-abstratas de Waters, ainda que sistematicamente presente em sua produção geometrizada, adquire maior literalidade nas esculturas/maquetes que a artista realiza na série Templo, ao longo da década de 1980. Nela, os jogos compositivos das figuras geométricas se materializam nos pedaços de madeira pintada, e apresentam efetivamente um corpo de edifícios oníricos, angulosos, e coloridos, que reverberam um indicativo de movimento muito presente em diversas de suas obras: um movimento de ascendência, de elevação do olhar contemplativo em direção a um plano que escapa a planaridade da tela.

Nesse encontro de disposições concretas com linhas de força mística, execução feminina e cores vibrantes não-primárias, já que Waters não faz uso de pigmentos puros saturados, mas preza pela mistura cromática em diversas gradações de contraste, reside uma tríade de elementos que convergem para um "descarte" da produção de Waters dentro do espectro dos concretismos nacionais - e a principal tática para essa exclusão é o silêncio da crítica e da historiografia, método largamente utilizado para a invisibilização das artistas mulheres.

Mesmo com exposições recentes na última década em galerias nacionais e internacionais, e algumas parcas publicações resultantes dessas investidas de mercado, acompanhadas por algumas peças jornalísticas mais informativas que analíticas, sucede um profundo silêncio crítico sobre a produção dessas duas artistas. Dentre ambas, Lauand segue sendo um aditivo mercadológico mais potente por seu vínculo direto com o GR do que Waters, que sempre teve dificuldade de aderência a grupos e coletivos, preferindo um caminhar solo em seu percurso profissional, e sequer possui estudos monográficos a respeito.

São esses dois casos aqui discutidos, mais hiatos pela perspectiva feminista em história da arte que precisam ser preenchidos, reconfigurados e reinterpretados, a fim de esgarçar a malha do cânone artístico.

\section{Referências}

ALBERRO, A. Abstraction in reverse: the reconfigured spectator in midtwentieth-century Latin American art. Chicago: The University of Chicago Press, 2017.

AMARAL, A. Projeto Construtivo Brasileiro na Arte. Museu de Arte Moderna, Rio de Janeiro. São Paulo: Pinacoteca do Estado de São Paulo, 1977.

BELLUZZO, A. M. Ruptura e arte concreta. In: AMARAL, Aracy (org.). Arte Construtiva no Brasil - Coleção Adolpho Leirner. São Paulo: Melhoramentos: DBA Artes Gráficas, 1998.

BRITO, R. Neoconcretismo: Vértice e Ruptura do projeto construtivo brasileiro. Rio de Janeiro: FUNARTE, 1985.
CHAJES, J. Blavatsky and the Lives Sciences. Aries - Journal for the Study of Western Esotericism, n.18, 2018.

COCCHIARALE, F.; GEIGER, A. B. Abstracionismo Geométrico e Informal. A vanguarda brasileira nos anos cinquenta. Rio de Janeiro: FUNARTE, 1987.

CORDEIRO, A. Waldemar Cordeiro: fantasia. Tradução John Norman; Marisa Shirasuna; Izabel Burbridge. São Paulo: Itaú Cultural, 2014.

Teoria e Prática do Concretismo Carioca. In: AD Arquitetura e Decoração, mar.abr. 1957.

EDELMAN, A.; DRISCOLL, J. (org.) Judith Lauand. Brazilian Modernist, 1950-2000s. New York: Driscoll: Babcock Galleries, 2014. 
Judith Lauand: Brazilian Concrete Abstractions. New York: Driscoll: Babcock Galleries, 2017.

ESPADA, H. O debate em torno da Primeira Exposição Nacional de Arte Concreta (19561957). In: ANNUAL CONFERENCE OF THE PROJECT, 4., 2007, Buenos Aires. ICAA Documents Project Working Papers. Houston: International Center for the Arts of the Americas, 2007, v. 1, p. 4-9.

FIORAVANTE, C. Judith Lauand Experiências. Museu de Arte Moderna de São Paulo, 2011.

GARCIA, M. A. Abstracción entre Argentina y Brasil. Inscripción regional e interconexiones del Arte Concreto (1944-1960). Tese (doutorado em Artes) - Facultad de Filosofía y Letras, Universidad de Buenos Aires, 2008.

El arte abstracto: intercambios culturales entre Argentina y Brasil. Buenos Aires: Siglo Veintiuno Editores, 2011.

GUILBAULT, S. Respingos na parada modernista: a invasão fracassada da arte abstrata no Brasil, 1947-1948. In: ARS, São Paulo, vol. 9, n. 18, p.148-173, 2011.

GULLAR, F.; CASTRO, A. de; WEISSMANN, Franz; CLARK, Lygia; PAPE, Lygia; JARDIM, Reynaldo; SPANUDIS, Theo. Manifesto Neoconcreto, Jornal do Brasil, Rio de Janeiro, p. 4-5, 22 mar. 1959.

Tentativa de Compreensão. Suplemento Dominical do Jornal do Brasil, Rio de Janeiro, 28 nov. 1959.

HENDERSON, L. D. The Fourth Dimension and Non-Euclidean Geometry in Modern Art: Conclusion. Leonardo, vol. 17, n. 3 , p.205-210, 1984.

HERKENHOFF, P. Judith Lauand. Obras de 1954-1960. São Paulo: Sylvio Nery da Fonseca Escritório de Arte,1996.

H. P. BLAVATSKY Theosophist. October, 1879. Disponível em: $<$ https://blavatsky.net/index.php/what-istheosophy>. Acesso em: 12 jul. 2020.

JAFFÉ, Hans C. De Stijl 1917-1931. The Dutch Contribution to Modern Art. Amsterdam: J.M. Meuhemhoff, 1956.

KERN, M. L. B. Um artista entre Europa e Novo Mundo: Joaquín Torres-García. Estudos IberoAmericanos, PUCRS, v. 38, supl., p. 150-159, nov. 2012.
MAGALHÃES, A. G. A disputa pela arte abstrata no Brasil: revisitando o acervo inicial do Museu de Arte Moderna de São Paulo, 1946-1952. Resgate - Rev. Interdiscip. Cult., Campinas, v. 25, n. 1 [33], p. 7-28, jan.-jun. 2017.

MATTAR, D. Jandyra Waters. Ritmo do tempo. São Paulo Almeida e Dale Galeria, 2015.

MOLINA, C. Judith Lauand: as ousadias e delicadezas de uma concretista. Estadão, São Paulo, 01 ago. 2007. Disponível em: $<$ https://cultura.estadao.com.br/noticias/geral,ju dith-lauand-as-ousadias-e-delicadezas-deuma-concretista,28221>. Acesso em: 27 set. de2020.

MORAES, Marcos. Jandyra Waters. São Paulo: Galeria Sancovsky, 2018.

NUNES, F. V. Waldemar Cordeiro: da arte concreta ao "popcreto". Dissertação (Mestrado em História) - IFHC-UNICAMP, 2004.

PEDROSA, M. Forma e percepção estética. São Paulo: EDUSP, 1996.

Acadêmicos e Modernos. São Paulo: EDUSP, 1998.

Artes Visuais. Pintura brasileira e moda internacional (1959). Disponivel em: $<$ Documents of 20th-century Latin American and Latino Art. A digital archive and publications project at the Museum of Fine Arts, Houston>. Acesso em: 20 mar. 2015.

PENNICK, N. Geometria Sagrada. Simbolismo e intenção nas estruturas religiosas. Tradução de Alberto Feltre. São Paulo: Editora Pensamento, 1980.

PUCU, I.; MEDEIROS, J.(orgs.) Roberto Pontual. Obra Crítica. Rio de Janeiro: Azougue Editorial, 2013.

PINSKY, C. B. Mulheres dos anos dourados. São Paulo: Editora Contexto, 2014.

RINGBOM, S. Art in 'The Epoch of the Great Spiritual': Occult Elements in the Early Theory of Abstract Painting. Journal of the Warburg and Courtauld Institutes, vol. 29, p. 386-418, 1966.

SPANUDIS, T. Arte Transcendente. São Paulo: Museu de Arte Moderna de São Paulo, 1981.

TORRES-GARCÍA, J. Universalismo Constructivo. Contribucion a la unificacion del arte y la cultura em américa. Buenos Aires: Colecion Aristarco Editorial Pseidon, 2000. 
TOSO, A. Retrato da artista Judith Lauand. Disponivel em: <www.revistabravo.com.br>. Acesso em: março de 2011.

VARELA, E. C. Arte concreta além da Europa. Brasil, Argentina e MAM-RIO. Rio de Janeiro: Museu de Arte Moderna do Rio de Janeiro, 2017.

WATERS, J. Pedras Nuas. Rio de Janeiro: José Olympio Editora, 1974.
Desvendador. São Paulo: DAG, 1977.

Ritmo do tempo. São Paulo: Scortecci Editora, 2001.

ZAGO, A. Doação ao MAC enriquece acervo da pintura brasileira. Suplemento Cultural do Jornal O Estado de São Paulo, São Paulo, 06 jan. 1980.

\section{Notas}

\footnotetext{
* Pós-doutoranda IEB-USP com financiamento CNPQ. E-mail: <ttrizoli@gmail.com>. ORCID: <https://orcid.org/0000-0001-6508$2076>$.

1 Os artigos "Tentativa de Compreensão" de Ferreira Gullar publicado no Suplemento Dominical do Jornal do Brasil em 28 de novembro de 1959, e "Teoria e Prática do Concretismo Carioca" de Waldemar Cordeiro, publicado pela revista AD Arquitetura e Decoração na edição de Março/Abril de 1957 são sintomáticos desses partidos estéticos em linguagem bélica de manifesto moderno.
}

2 Vide o livro de Ronaldo Brito Neoconcretismo: Vértice e Ruptura do projeto construtivo brasileiro, e a compilação Abstracionismo Geométrico e Informal. A vanguarda brasileira nos anos cinquenta, organizada por Fernando Cocchiarale e Anna Bella Geiger. Vale notar também alguns artigos de Mario Pedrosa, como "Grupo Frente e Paulistas e Cariocas", integrantes da coletânea Acadêmicos e Modernos publicado pela EDUSP em 1998.

${ }^{3}$ Que aliás podem ser rastreadas desde a icônica Figuração e Abstração (Magalhães, 2017) no MAM-SP em 1949 que instaura a discussão abstracionista no Brasil (Guilbault, 2011), seguida pela 1ª Bienal de São Paulo e o primeiro prêmio a Max Bill (1908-1994), a I Exposição Nacional de Arte Concreta em 1956 que do MAM SP seguiu para o MAM RJ (Espada, 2007), mas também a mostra do Grupo de Artistas Modernos Argentinos em 1953 no MAM RJ e a $1^{2}$ Exposição Nacional de Arte Abstrata no mesmo ano, primeiramente no MAM SP, seguido pelo MAM RJ e depois no Hotel Quitandinha, em Petrópolis.

${ }^{4}$ Maria Amalia Garcia comenta sobre o caráter assertivo da mostra do Grupo Ruptura: "A mostra Ruptura, que contou com cerca de cinco obras de cada artista, foi, na medida em que implicou o reconhecimento institucional dessa tendência como força coletiva ativa nas artes plásticas brasileiras, uma estratégia para legitimar e dar corpo à proposta" (Garcia, 2011: 159).

5 "Enfim, o ponto alto da mostra com dois representantes do concretismo, o pintor Lohse que desenvolve as conquistas do grupo Stijl - o seu quadro Tema em Duas Dimensões é o mais expressivo da Bienal - e o escultor Max Bill, proveniente dos ensinamentos da Bauhaus, é hoje a intuição artística mais atenta, tendo contribuído eficazmente para a introdução nas representações pictóricas e esculturais de novas categorias estéticas, fundadas em noções da "Guestalt", das teorias relativísticas da matéria e na matemática enedimencional, particularmente referindo-se à topologia. Unidade Tripartidaria tem sua origem intelectual no problema da fita "Moebius" e desenvolve expressivamente a "dupla superfície" que, por uma única linha, é ligada em movimento continuo, ao espaço infinito" (Cordeiro, 2014: 170).

6 "As relações entre Bill e alguns artistas, críticos e gestores argentinos e brasileiros geraram momentos de interlocução e espaços de intervenção. Bill encontrou na América do Sul possibilidades de diálogo e ação que resultavam impensáveis para sua situação no âmbito europeu do pós-guerra, no qual a arte concreta suiça (representada pelo grupo Allianz) teve escassa projeção. Em contraposição, deste lado do Atlântico o concretismo encontrou um forte impulso e Bill foi uma figura-chave nessa articulação" (Garcia, 2008: 197).

${ }^{7} \mathrm{~A}$ pesquisadora Elisabeth Catoia Varela comenta sobre essa fortuna crítica: "Lendo a bibliografia sobre arte concreta no Brasil, percebo uma narrativa linear, regida por ordem cronológica que apresenta o modo como ocorreram os movimentos de tendência abstratogeométrica na Europa e sua recepção e vivência no Brasil. Nessa narrativa tradicional, Max Bill é o personagem historicamente mais destacado. Aos artistas brasileiros, restaria estudá-lo para produzir obras de acordo com seu legado" (Varela, 2017: 128).

8 Todas as traduções livres são da autora.

${ }^{9}$ A divisão abissal entre o campo das ciências e o campo das religiões, e consequentemente dos misticismos (e entendendo aqui religião como um corpo dogmático e misticismos como práticas mais difusas de experiências com o divino), foi fortemente acentuada ao longo do século XIX, justamente um período em que a Revolução Industrial e a veridicção discursiva das ciências aliam-se a fim de solidificar os projetos modernos de vida. No entanto, essa divisão sempre foi mais frágil do que aparenta, já que justamente nesse período crucial de solidificação do universo científico como território de produção de verdades sucede os questionamentos dos métodos de análise e comprovação de argumentos e fatos. Nesse sentido, vale a pena retomar o estudo já clássico de Tomas $\mathrm{S}$. Kuhn, $A$ Estrutura das Revoluções Científicas, sobre os percursos históricos de consagração do campo científico e seus métodos de análise do mundo, onde fica evidente a flutuação das metodologias e as negociações narrativas estabelecidas pelo campo justamente para consolidá-lo, e suas resistências de abertura e diálogo com outros territórios de episteme. Sobre o tópico específico entre o campo científico e a teosofia, vide o seguinte excerto do artigo de Julie Chajes: "O espiritualismo teve um lugar significativo nas discussões em torno da ciência e da religião, e muitos cientistas proeminentes se interessaram por ele. Enquanto alguns acreditavam que os 
fenômenos das sessões espíritas eram sobrenaturais, outros acreditavam que forças naturais estavam por trás deles. A ciência ainda não tinha identificado isso, mas eles pensaram que eventualmente o faria" (Chajes, 2018: 266).

${ }^{10}$ Agente mística e intelectual de origem húngara, responsável pelo desenvolvimento e divulgação da Teosofia como um novo campo de conhecimento no século XIX. Sua figura é permeada por mitologias de origem e criação, e escândalos em relação às assertivas da filosofia com o campo científico.

11 "Os europeus, acostumados inconscientemente com uma velha ideia da superioridade metropolitana de seu Continente em matéria de civilização e de arte, uma vez afeitos à linguagem moderna - coisa que só conseguem após tremendos esforços para sair dos cânones tradicionais de seus respectivos países - passam ingenuamente à exigir de todos os países, sobretudo os novos, uma adequação estreita dos artistas não europeus nos moldes últimos da Europa. Fora disso, o que querem é o exótico" (Pedrosa, 2015). ${ }^{12}$ Ainda que as delimitações dos preceitos da teosofia sejam difusas e flutuantes, vale tomar a palavra diretamente à sua criadora, para verificarmos suas referências: "Teosofia é, então, a arcaica Religião-Sabedoria, a doutrina esotérica uma vez conhecida em todos os países antigos com pretensões de civilização. Esta "Sabedoria", todos os antigos escritos nos mostram como uma emanação do Princípio divino..." (H. P. Blavatsky, 1879).

${ }^{13}$ Mas a convergência entre arte e teosofia se dava principalmente no objetivo comum de materialização de um corpo teórico que demonstrasse a existência de fenômenos ditos fantásticos, como as representações da aura humana, a geometria sagrada, a quarta dimensão, e uma suposta harmonia e ordenação universal em meio ao caos do mundo - ou seja, o fascínio desenvolvido pelos artistas sobre a teosofia residia nas possibilidades de investigação de universos para além do mundo visível e matérico, dentro de um discurso que recuperava o caráter de benção divina da criação artística. Já para a congregação teosófica, interessava a presença de artistas em seu séquito por suas relações simbólicas de poder com a elite e sua capacidade de representar uma nova ordem divina de reencantamento do mundo.

14 Torres-García absorveu na Europa as tradicionais e as novas concepções e práticas artísticas, as reelaborou ao resgatar as raízes culturais latino-americanas e signos primitivos e místicos, criando os próprios conceitos de arte e poéticas. Fez projeções utópicas de ordem cultural e espiritual para a América Latina, cujas ideias permearam também as suas obras, num momento de crise do materialismo e de crença na possibilidade de surgimento de um novo homem e de unidade dos povos (Kern, 2012: S158).

${ }^{15}$ A relevância de Torres-García se dá nessa discussão por dois aspectos: o primeiro é sua influência no imaginário concreto brasileiro, ainda que tardiamente, já que o artista, antes da fatídica individual de 1978, teve obras expostas em pelo menos três Bienais de São Paulo em período anterior à deflagração dos grupos GR e GF; o segundo aspecto é justamente sua capacidade de introjetar um caráter sensivel e mitológico num vocabulário estético que seguia racionalmente depurado em nosso circuito.

${ }^{16} \mathrm{~A}$ intensidade dessa narrativa hiper-racionalizada das forças concretas no âmbito latino-americano permanece no referencial crítico ainda nos dias atuais. Tomemos como exemplo aqui a seguinte definição de Alexander Alberro sobre esses movimentos como exemplo das negociações discursivas e conceitos caros aos concretismos: "Em seu esboço das bases da pintura concreta, Van Doesburg elaborou sobre estes pontos: 'Em sua busca pela pureza os artistas eram obrigados a abstrair das formas naturais nas quais os elementos plásticos estavam escondidos, a fim de eliminar as formas naturais e substituí-las por formas artísticas. Hoje, a ideia de forma artística é tão obsoleta quanto a ideia de forma natural. Estabelecemos o período da pintura pura construindo a forma espiritual'. Van Doesburg usou o termo espiritual para significar "mental" ou "ideativo", para significar invenção, a concepção de formas inteiramente novas: ' $O$ espírito criativo se torna concreto. Falamos de pintura concreta e não abstrata porque nada é mais concreto, mais real do que uma linha, uma cor, uma superfície'." (Alberro, 2017: 17).

17 "A chave para a compreensão das posições de Cordeiro em relação ao construtivismo está em um texto, não-datado, chamado 0 suprematismo, o neoplasticismo e o construtivismo do ponto-de-vista da pura visualidade, destinado a uma conferência. A visão sobre o construtivismo russo expressa neste texto denuncia a compreensão dominante, na época em que Cordeiro vivia, sobre a vanguarda soviética... Cordeiro sucumbe, aqui, ao erro historiográfico a que o Ocidente foi induzido através da divulgação do construtivismo de Naum Gabo... na Europa, que o esvaziou dos seus componentes ideológicos originais." (Nuner, 2004: 16).

${ }^{18}$ Brito efetua um levantamento das principais linhas de força conceituais do concretismo brasileiro, asseverando uma égide racionalista via De Stijl, Bauhaus, Escola de Ulm, Cordeiro e Gullar, a fim de justificar o rompimento do neoconcretismo devido ao dogmatismo programático dos concretos paulistas e por uma suposta alienação político-social desses artistas em relação à contingência brasileira. "As ideologias construtivas estão organicamente ligadas ao desenvolvimento cultural da américa Latina no período de 1940 e 1960. Encaixavam-se com perfeição nos projetos reformistas e aceleradores dos países desse continente e serviram, até certo ponto, como agentes da libertação nacional frente ao domínio da cultura europeia, ao mesmo tempo em que significavam uma inevitável dependência desta. A pergunta óbvia é a seguinte: de que maneira elas poderiam servir à emancipação cultural desses países frente as suas tradições colonizadas?" (Brito, 1985: 47).

${ }^{19}$ No catalogo resultante da exposição Projeto Construtivo Brasileiro na Arte, realizado em 1977 na Pinacoteca de São Paulo com curadoria de Aracy Amaral, percebemos a sedimentação das interpretações racionalizantes e progressivas sobre o movimento concreto brasileiro, agora apresentado como um projeto estético-social, mais do que um grupo artístico de vanguarda, e que teria como primeira manifestação a Semana de Arte Moderna de 1922 - uma tentativa de consolidação do protagonismo paulista em detrimento das trocas com os agentes cariocas, e que requenta uma já velha disputa por liderança estética entre o eixo Rio-São Paulo. "Enfim, o pragmatismo do meio paulista comandou o espetáculo em São Paulo assim como a envolvência, a liberdade de ser carioca apelou aos sentidos num impulsionamento ao expressar-se de forma mais intensa..." (Amaral, 1977: 316).

20 Pontual, ainda que localize uma germinação primeira das questões construtivas na arte brasileira também nos primeiros eventos modernos, procura salientar um caráter pulsional e sensivel de nossas projeções construtivistas, relacionando de modo enfático os ecos de Torres-García no mesmo patamar que Max Bill. "Praticamente todos os movimentos e correntes da arte moderna, desde 0 princípio do século, viam-se participantes da I Bienal de São Paulo: o expressionismo, o cubismo, o futurismo, o surrealismo, algum construtivismo (Joaquím Torres-García lá estava), a abstração lírica, gestual ou geométrica, e a arte concreta - a ausência maior ficava por conta do dadaísmo" (Pontual, 2013: 446). 
21 "Esta bienal foi uma oportunidade sem paralelo para artistas emergentes, e para Lauand, especificamente, enquanto o modernismo se desenrolava diante de seus olhos. Além de galerias especiais dedicadas a artistas individuais, havia em exibição exemplos monumentais de De Stijl, cubismo e futurismo. As esculturas cinéticas e móbiles de Alexander Calder flutuaram na companhia dos desenhos intrincadamente tecidos de Paul Klee e da angustiada obra-prima de Picasso, Guernica (1937), buscaram um diálogo momentâneo com a pura tensão rítmica do falecido Broadway Boogie Woogie de Mondrian (1942-43)" (Edelman, 2017: 04).

22 "Há uma identidade substancial entre as ideias de Gullar e a sobras dos concretistas do Rio. A problemática surrada do neoplasticismo, reduzido a um esquema primário e ortodoxo de fundo e figura, sem rigor estrutural e principalmente, sem rigor cromático, serve de apoio e cabide ao lirismo expressivo que se dilui, sem mote preciso, nos meandros do labirinto de arte abstrata. Veja-se Ivan Serpa, para se ter uma ideia do grau de desnorteamento dos nossos colegas cariocas. Até marrom há nesses quadros. Mas os requintes tonais, dignos de Milton Da costa, não bastam para camuflar a pobreza da idéia. Como já viu Mario Pedrosa" (Cordeiro, 2014: 220).

23 "Claro que Lauand usou cores limitadas em seus primeiros trabalhos, no entanto, ao longo dos anos 1960 e até meados de 1970 e pouco adiante, ela direcionou sua atenção à interação das cores no espaço... ao longo do período tardio de sua carreira, ela tem aplicado cores vibrantes a suas estruturas compositivas originais." (Edelman, 2014: 17).

${ }^{24}$ É possível inclusive, partindo do título dado por Lauand, considerar que esse movimento de gradação de um círculo central em direção a uma forma ovalada, resultante do contorno efetuado pela volumetria das pontas dos triângulos, faça referência ao aparato simbólico da mística teosófica, no caso o símbolo da Vesica Piscis, onde a intersecção entre duas esferas resulta numa forma ovalada de pontos agudos. Este símbolo, presente em diversos círculos místicos, faz referência ao encontro das duas polaridades do universo, representadas pelas duas esferas simétricas que correspondem ao mundo material e divino, sendo a forma ovalada angulosa no centro, também nomeada vez por outra como ovo cósmico, o território de encontro e atuação das transcendências fantásticas (Pennick, 1980: 20). Se essa correlação mística é possível no trabalho de Lauand, considerando a vertente encantatória das modernidades geometrizantes que apontamos anteriormente, é mais pertinente apontar em sua produção a especifidade da palheta pictórica, já que a constatação de tais referências religiosas na trajetória da artista é hoje complexa devido ao avanço de sua idade e fragilidade física. ${ }^{25}$ Vale notar, mais uma vez, que nas estruturas compositivas de Lauand vez ou outra surgem referências a uma possível influência teosófica em suas obras. No caso das telas Sem Título de 1955 e Espaço Virtual de 1960, o eixo vertiginoso centralizado eleito pela artista assemelha-se às composições de mandalas utilizadas para as práticas de meditação, assim como os recursos geométricos correlacionam-se aos ditos sólidos platônicos apresentados no Timeu, em que o filósofo estabelece equivalências matemáticas que convencionam todos os supostos estados da matéria (Pennick, 1980: 76).

26 "Realmente, a parte mística sempre esteve presente em minha vida. Ela faz parte do meu ser. Sempre me inclino para o lado espiritual das coisas". Entrevista concedida à autora por e-mail, em 22 jul. 2020

${ }^{27}$ Mesmo Lauand, católica fervorosa, não explicita o aspecto de experiência religiosa em sua obra, deixando en passant tais elementos (Edelman, 2014: 19 nota 48).

${ }^{28}$ Entrevista concedia à autora por e-mail, em 27 jul. 2020

29 Jandyra Waters publica três livros de poesia: Pedras Nuas, em 1974, Desvendador, em 1977 e Ritmo do tempo, em 2001.

Artigo recebido em setembro de 2020. Aprovado em dezembro de 2020. 